\title{
TOURISTS RESPONSES TO THE USE OF MOBILE AUGMENTED REALITY FOR TRAVEL
}

\author{
Nur Shuhadah Mohd ${ }^{1}$ \& Hairul Nizam Ismail ${ }^{2}$ \\ ${ }^{1}$ Department of Tourism, Kulliyyah of Languages and Management, \\ International Islamic University Malaysia \\ ${ }^{2}$ Faculty of Built Environment and Surveying, Universiti Teknologi Malaysia \\ (shuhadah@iium.edu.my, b-hairul@utm.my)
}

\begin{abstract}
Tourist experiences are shaped by the complexities of the individual visitor's psychological factors, and it is widely known that tourists anticipate a positive experience from every trip made. Yet, the fact remains that travel is inextricably linked to the issues of geography and awareness and a misinterpretation of the attributes of a destination may lead to unlikely expectations that affect the entire experience. With the dynamic and interactive visualisation features offered by augmented reality (AR) on mobile phones and other smart handheld devices, this technology is viewed as being capable of closing the gap between tourist expectations and reality, thereby improving how tourists engage with their surroundings. Despite the known potential of this relatively new technology, its actual acceptance among the users is still minimal, especially in the Malaysian context. Considering this limitation, this study examined the extent of AR utilisation and its ability to influence the development of a tourists' travel experience. The 'Iskandar.my' mobile AR app was used in this research to evaluate the tourists' expectations, perception and satisfaction with the utilisation of this software platform to add value to their travel experience. The findings indicated that there was a statistically significant differences in the respondents' experiences before and after using the AR content on the mobile app. The thrill associated with the use of this advanced technology was the primary factor in their satisfaction with the AR function. However, the lack of variety in the attractions covered, as well as the app's currently limited offerings, were noted as factors that could affect the 'Iskandar. my' apps competitiveness with regard to other travel-related apps. Therefore, this researcher recommends that the developer of the app improve the design and service dimensions of the app to meet users' travel needs.
\end{abstract}

KEYWORDS: Mobile augmented reality, tourists experience, destination engagement, interpretation

\section{PURPOSE AND BACKGROUND}

The formation of tourist experiences involves complex process within the inner-mind. The positive and negative experiences of a destination is subject to an individuals' psychological factors including his or her emotional state, character and values (Larsen, 2007). With the current advancement in technology, tourists have become more empowered and sophisticated in information acquisition and decision-making, thanks to the progression of Information and Communications Technology (ICT) (Buhalis et al., 2011; Gretzel et al., 2006).

In relation to mobile technology engagement, the dynamic interaction with places of interest that users obtain and their ability to share travel experiences with friends and family in real-time via digital devices and social networking sites brings in a new form of tourist-destination interaction, enabling tourists to engage with destinations from a different yet unique perspective (Neuhofer, 2016). 
This is one of the important things that can add a new dimension to the tourists experience and is one that industry players should be aware of and try to capitalise on in their bid to meet and satisfy the tourists sophisticated and increasingly more complex demands (Kounavis et al., 2012; Linaza et al., 2012).

This study therefore aims to understand the tourist's response to the use of AR technology as a travel guide and the study will also examine the extent to which the use of AR technology influences the development of a tourists travel experience.

\section{METHODOLOGY}

This research used a quantitative method and questionnaires to gather the data for the study. The 'Iskandar. my' AR app was selected as the app to be used in this study as it was the only destination-based AR app available in Malaysia.

The respondents were selected via a purposive sampling method targeting the current and potential users of the 'Iskandar.my' app that have visited the Iskandar region in Malaysia. A summative evaluation was then applied to this research as it is the most well-suited to assessing the impact of an intervention on a target group, in this study that means the impact of mobile AR apps use on tourist responses.

The execution of summative evaluation in this study involved two steps;

1) execution of experimental session,

2) answering of the questionnaire survey.

As the app 'Iskandar.my' might be new to some respondents, they were requested to undergo a testing session with the app to test it and familiarize themselves with its use prior to answering the questionnaire. Respondents were given time to explore the app and to answer after they had finished testing the app.

\section{FINDINGS}

Table 1 shows the pair sample t-test of respondents' expectation and satisfaction towards the use of 'Iskandar. my' as mobile AR travel guide. The statistical findings signify the respondents actually encountered more positive changes compared to previous experiences with the AR content of the 'Iskandar.my' adding positive value to the attractions and the way the tourists interacted with them at destinations in the Iskandar region. The test also proved the presence of the app and its use significantly altered the respondents' experience with regard to how tourists explored the destination, the dynamics of the interactions at the destination, and the uniqueness of the travel experience. The positive changes in tourists' responses can be directly linked to the distinctive 3D viewing feature of the mobile AR app that positively influences the user's psychological state.

Table 1: Paired sample t-test of respondents' responses

\begin{tabular}{cccccc}
\hline \multirow{2}{*}{ Tourist Responses } & Expectation & Satisfaction & \multicolumn{2}{c}{ Paired Differences } & \multirow{2}{*}{ p-value* } \\
\cline { 4 - 5 } & & & Mean & Std. dev. & \\
\hline Destination knowledge & 3.80 & 4.08 & 0.21 & 1.128 & 0.040 \\
Destination exploration & 3.78 & 4.16 & 0.27 & 0.930 & 0.002 \\
Dynamic interaction & 3.85 & 4.18 & 0.23 & 0.897 & 0.006 \\
Unique experience & 3.72 & 4.07 & 0.25 & 0.978 & 0.006 \\
\hline${ }^{*} p$-value is significant at $<0.05$ & & & & \\
\hline
\end{tabular}




\section{CONCLUSION}

The significant improvement in the respondents' experience before and after using the mobile AR features in the 'Iskandar.my' app is seen as a result of the psychological influence of the app in creating a unique virtual experience for each individual tourist. However, the app seems to have only limited information on points of interest at each of the travel destinations, which may result in the selection of other travel apps among its existing users to gain more extensive and inclusive services and information.

Despite the limitations in the performance of the 'Iskandar.my' app, its ability to significantly enhance the experience of its users successfully illustrates the capability of AR technology to influence the psychology of its users by making the destination seem more attractive than it usually is.

With reference to the analysis, findings and recommendations proposed in this research paper, it can be concluded that the use of mobile AR technology for tourism-related purposes does influence the psychology of its users and can enhance their travel experience.

\section{CONTRIBUTION/PRACTICAL IMPLICATIONS}

Employing the AR technology without further consideration of the users' need for information would not be an effective means of facilitating positive travel experiences. Therefore, it is recommended that the app expand on the breadth of topics covered and depth of the information provided, such as history and background of places of interest and the diversity of the attractions on location, to better fulfil the end-users' information needs and facilitate the better execution of travel activities. In improving the performance and the ability of the 'Iskandar.my' app to influence of end-users' experiences, it is recommended that the app enrich its AR offerings by adding information and links to more diverse forms of media such as videos and websites which contain relevant historical information among other things to better enhance the users sensory and emotional attachments to the destination and help them to create a positive and memorable travel experience.

\section{REFERENCES}

Larsen, S. (2007). Aspects of a psychology of the tourist experience. Scandinavian Journal of Hospitality and Tourism, 7(1), 7-18. https://doi.org/10.1080/15022250701226014

Linaza, M., Marimón, D., Carrasco, P., Álvarez, R., Montesa, J., Aguilar, S., \& Diez, G. (2012). Evaluation of Mobile Augmented Reality Applications for tourism destinations. Information and Communication Technologies in Tourism 2012 SE - 23, March 2011, 260-271. https://doi.org/10.1007/978-3-70911142-0_23

Neuhofer, B. (2016). An exploration of the technology enhanced tourist experience. European Journal of Tourism Research, 12, 220-223. 